\title{
PLURALISME DALAM PROBLEMA
}

\begin{abstract}
Achmad
Abstrak

Pluralisme yang dimaksudkan dalam tulisan ini adalah pluralisme agama. Pluralisme dalam bidang itu telah lama diperdebatkan oleh sebagian cendekiawan agama. Hampir di setiap agama besar semisal Yahudi, Kristen, dan Islam muncul tokoh pluralisme yang berjuang dengan tulisannya menawarkan dan meyakinkan setiap pemeluk agama apapun, bahwa semua agama hakekatnya sama. Pluralisme beda dengan pluralitas, pluralitas ada yang sunnatullah yang memang terjadinya dikehendaki oleh Allah swt. dan pluralitas yang dikehendaki oleh manusia atau pluralitas yang anthroposentris, artinya bersumber dari manusia dan untuk manusia.Dengan landasan teori theologi global atau theologi universal konsep pluralisme diupayakan ingin menyelamatkan manusia dan peradabannya dari kerusakan yang disebabkan oleh pemeluk agama yang bermusuhan, menyerang bahkan membunuh pihak yang berbeda keyakinan keagamannya. Muslim yang berpaham pluralisme berarti seorang yang ragu terhadap ajaran agamanya dan disebut musyrik karena mempercayai sama hakekat ajaran Tuhan dalam agamanya dengan Tuhan agama lain. Dosa besar bagi muslim yang berpaham pluralisme bila sebelum mati dosanya tidak ditaubati, selamanya tidak mendapatkan ampunan Allah swt. Seorang muslim imannya harus kokoh dan khalis serta yakin agamanya satu-satunya yang benar yang mengantarkan kesematan hidup di dunia dan di akhirat.
\end{abstract}

Kata kunci :Pluralisme, pluralitas, theologi global, theologi universal, syirik, khalis.

Kata pluralisme yang kata asalnya plural, sering diterjemahkan sebagai jamak atau majemuk dan dibelakang kata plural ditambah isme yang berarti paham atau keprcayaan. Sebagian penulis menyambung pluralisme dengan kata agama, sehingga menjadi pluralisme agama. Pluralisme dalam tulisan ini adalah pluralisme agama.

Dalam alur sejarah, pluralisme sebagai suatu konsep paham kepercayaan tidak tiba-tiba muncul, artinya keberadaanya ada yang mendahului yaitu paham liberalisme. Sebagian orang memaham bahwa pluralisme sama dengan pluralitas, padahal sebenarnya berbeda walau memiliki asal kata yang sama yaitu plural. Ada cendekiawan Muslim sebagai pengusung pluralisme, meyebarkan paham tersebut yang diakui sebagai paham yang benar.

Pergumulan paham yang berbeda tentang konsep paham tersebut terus berlangsung sampai saat ini, artinya yang setuju terus mempertahankan dan 
berusaha meyakinkan dan menyebarkannya memalui berbagai media masa, yang tidak setuju berusaha melemahkannya.

Kelompok lain yang jumlahnya sangat banyak tidak mengetahui apa pluralisme itu. Mereka pada umumnya bergembira bila ada tokoh Muslim yang mendapat sebutan sebagai tokoh atau bapak pluralisme.

Tulisan ini berupaya memaparkan pluralisme dan bagaimana sebenarnya bila dikaji menurut ajaran Islam, dan pengaruhnya terhadap keimanan dan ke-Islaman seseorang. Tulisan ini diharapkan menjadi pencerah keimanan dan ke-Islaman seseorang, sehingga imannya menjadi kokoh dan khalis, mapan dan mantap dalam ber-Islam.

\section{Pluralitas dan Pluralisme}

Pluralitas sebagai kemajemukan dalam kehidupan manusia suatu keniscayaan, dan Islam menyebutnya sunnatullah,walau tidak semua yang terlihat dalam kehidupan ini pasti sunnatullah. Tentang hal ini surah Al Hujurat ayat 13, menyatakan yang artinya;

"Hai manusia, sesungguhnya Kami menciptakan kamu dari seorang lakilaki dan seorang perempuan serta menjadikan kamu berbangsa-bangsa dan bersuku-suku supaya kamu saling kenal mengenal. Sesungguhnya yang paling mulia diantara kamu disisi Allah ialah yang paling bertaqwa diantara kamu. Sesungguhnya Allah Maha Mengetahui lagi Maha Mengenal.”

(QS: Al Hujurat ayat 13)

Ayat di atas menegaskan bahwa dasar pluralitas pada ciptaanNya, yaitu manusia yang berbeda kebangsaannya dan kesukuannya. Al Qur-an menyebut garis besarnya dalam penciptaan sedang rinciannya terlihat nyata pada realitas kehidupan manusia.

Ada bermacam-macam agama besar di dunia ini seperti Yahudi, Kristen, Katholik, Islam, Hindu, Budha serta banyak pula aliran kepercayaan. Semua agama tersebut menurut Islam terbagi menjadi dua yaitu agama samawi dan agama ardli. Yang pertama, agama samawi yang artinya agama langit yang diturunkan dari langit 
secara wahyu oleh Allah swt. melalui malaikat Jibril yaitu agama Yahudi, , Nasrani (Katholik, Kristen), dan Islam. Agama Yahudi dan Nasrani sudah tidak asli lagi sebagai agama wahyu, nama agama itu sudah dinisbahkan kepada bangsa dan nama pembawa agama tersebut. Dengan kata lain, agama wahyu campur dengan agama budaya, ajaran keTuhanannya sudah berbeda dengan agama tauhid atau monotheisme murni. Sedang Islam yang diturunkan kepada Nabi Muhammad saw. tidak mengalami perubahan. Nama agama ini tidak dinisbahkan dengan nama tempat atau orang sebagai pembawa agama, yang menurut W.C.Smith disenut Suie Generis.

Kedua agama ardli, yang sering disebut agama budaya, karena tumbuh di bumi dari budaya manusia. Sebenarnya setiap manusia memiliki fitrah atau dasar pembawaan beragama yang fitrah, karena yang dijumpai dan dipilih bukan agama yang fitrah maka manusia beragama budaya. Dalam kehidupan manusia hak yang paling asasi adalah beragama, ini menunjukkan pluralitasnya manusia dalam beragama.

Allah swt. berfirman di dalam surah Al Kafirun ayat 6, "Lakum dinukum waliyadin. Bagimu agamamu dan bagiku agamaku."Allah swt. memberikan kebebasan kepada manusia untuk memilih dan memeluk agama, manusia tidak dipaksa untuk beragama Islam.

Pluralitas dalam beragama Islampun dijumpai, bukankah di alam Fiqh ibadah terdapat berbagai madzhab. Madzhab Hanafi, madzhab Maliki, madzhab Syafi'i, madzhab Hambali. Di dalam madzhab-madzhab tadi ada perbedaan furuiyah yang itu tetap sah.

Di dalam ibadah Jum'ah, Rasulullah Muhammad saw. melaksanakan dengan satu adzan dan ini berdasar hadits yang shahih. Juga ada ibadah Jum'ah yang adzannya tidak hanya satu kali tetapi dua kali. Ini pertama kali terjadi pada masa Khalifah Utsman bin Affan ra. Umat Islam pada saat itu jumlahnya sudah sangat banyak dengan berbagai aktifitas kehidupannya, maka adzan pertama dikumandangkan untuk menyeru umat agar segera menghadiri ibadah Jum'ah. Sedang adzan ke dua sama dengan yang Rasulullah saw. laksanakan, yaitu setelah 
khatib naik ke mimbar untuk berkhutbah. Kedua cara ibadah Jum'ah dengan adzan satu kali atau adzan dua kali, salah satunya sah untuk dilaksanakan.

Dari paparan di atas adalah pluralitas yang sunnatullah, yaitu Allah swt. yang menghendaki.Pluralitas yang tidak sunnatullah, contoh budaya manusia yang bermacam-macam sekedar produk kehendak manusia yang tidak berkesuaian dengan kaidah agama. Dalam tulisan tokoh Islam liberal, pluralisme berasal dari paham liberalisme, di sini pluralisme tidak terpisah dengan liberalisme.

Ada dua ayat di dalam Al Qur-an yaitu surah Al Baqarah ayat 62 dan surah Al Maidah ayat 69 yang dijadikan hujjah bahwa Al Qur-an mengajarkan pluralisme, yang terjemahnya sebagai berikut,"Sesungguhnya orang-orang yang beriman,orangorang Yahudi,orang-oramng Nasrani, dan orang-orang Shabi'in, siapa saja diantara mereka benar-benar beriman kepada Allah, hari kemudian dan beramal shalih, mereka akan menerima pahala dari Tuhan mereka,tidak ada kekhawatiran bagi mereka dan tidak pula bersedih hati."

"Sesungguhnya orang-orang yang beriman, orang-orang Yahudi, orangorang Shabi'in, orang-orang Nasrani, siapa saja diantara mereka yang benar-benar beriman kepda Allah dan hari kemudian dan beramal shalih, maka tidak ada kekhawatiran bagi mereka dan tidak pula bersedih hati."

Pengusung paham pluralisme menerangkan Al Qur-an dengan caranya sendiri. Cara itu tidak menggunakan kaidah keilmuan tafsir, sedangkan para ulama tafsir telah meletakkan dasar-dasar keilmuan tafsir untuk menafsirkan Al Qur-an. Oleh karena itu dalam memaham Al Qur-an hendaklah menggunakan cara sebagaimana telah dijelaskan oleh para ulama tafsir itu.

Di dalam kitab tafsir Al Azhar yang ditulis Buya Hamka, surah Al Baqarah ayat 62 dan surah Al Maidah ayat 69 diawali dengan kalimat,"Sesungguhnya orangorang yang beriman....”Yang dimaksudkan orang-orang yang telah beriman kepada Allah swt.dan beriman kepada Nabi Muhammad sw. sebagai Rasulullah, dan beriman kepada Al Qur-an sebagai wahyu Allah swt yang diturunkan kepada Nabi Muhammad saw.dan menjadi tuntunan hidup. “...dan orang-orang Yahudi, adalah bangsa yang menjadi kaum Nabi Musa as. dan Taurat sebagai kitab sucinya. “...dan orang-orang Shabi'in, di dalam Al Qur-an lafal yang semacam itu terdapat di tiga 
tempat,yaitu di surah Al Baqarah ayat 62, di surah Al Maidah ayat 69 dan di surah Al Hajj.

Kata Shabi'in itu berasal dari kata Shabi' yang artinya yang keluar dari agamanya dan membuat agama baru yang dianggapnya lebih sempurna. "...dan orang-orang Nashara," adalah kaumnya Nabi Isa as.Yahudi kaumnya Nabi Musa as., Nashara kaumnya nabi Isa as, dan Shabi'in kaum yang keluar dari agama yang dipeluk, bila mereka beriman kepada Allah swt., beriman kepada hari kemudian, beriman kepada Nabi Muhammad saw., beriman kepada Al Qur-an dan beramal shalih akan mendapatkan pahala dan hidupnya dijamin oleh Allah swt. tidak merasakan kekhawatiran dan tidak merasakan sedih.

Tokoh pluralisme menafsirkan dua ayat tesebut bahwa pemeluk agama Yahudi, Nasrani, Shabi'in bila beriman kepada Allah swt. dan beriman kepada hari kemudian dan beramal shalih,semua akan selamat. Bahkan pemeluk agama apapun mendapat keselamatan dalam kehidupannya. Hal ini disebabkan karena di dalam setiap agama terdapat kebenaran. Kebenaran itu tidak hanya dimiliki oleh satu agama saja. Semua pemeluk agama apapun akan menuju ke Tuhan yang satu, walau namanya berbeda-beda akan tetapi hakekatnya adalah sama. Nisbahnya di dunia ini banyak sungai yang diumpamakan agama dan setiap aliran air sungai itu bermuara ke laut yang sama yaitu samudera, dengan demikian dapat diartikan bahwa semua pemeluk agama akan menuju ke Tuhan yang sama.

\section{Sejarah Pluralisme}

Pluralisme agama berasal dari orang-orang yang berpikian bebas atau liberal, mereka memandang agama tidak memberikan keluasan dalam berpikir, maka keluarlah mereka dari kungkungan agama yang tidak bisa menjawab berbagai tantangan zaman, menuju berpikir bebas mendobrak berbagai kemandegan dan kemunduran, kejumudan dan berbagai perselisihan dan permusuhan.

Superioritas akal yang sering disebut rasionalis ini membentuk paham raionalisme. Dengan model ini, di barat tercatat ada Yahudi Liberal yang dengan pemikirannya menjebol tradisi Taurat. Bolehnya laki-laki kawin dengan laki-laki, 
atau perempuan kawin dengan perempuan, ini sejarah pertama Rabbi-Rabbi Yahudi Liberal yang mengesahkan perkawinan lesbian dan homoseksual.

Taurat, dalam Imamat 13 mengatakan,"Bila seorang laki-laki tidur dengan laki-laki seperti bersetubuh dengan perempuan, ke duanya telah berbuat keji dan harus dihukum mati." Ayat di atas bertentangan dengan hak asasi manusia yang paling asasi hak untuk kawin walau dengan sejenisnya.

Liberalisasi muncul antara lain sebagai disebut di atas dan sebab konflik antara orang-orang yang ada di sinagog dengan orang-orang luar, dan Nasrani, konflik anatara gereja dengan kehidupan di luar gereja. Keinginan menyelsaikan masalah konflik yang berasal dari sikap keberagamaan itu diwacanakan theologi global.

Bila diamati, theologi global yang dimaksud lebih bersifat politis, karena pertumpahan darah antar sekte, kelompok, madzhab terjadi. Maka tokoh pemikir mempertanyakan tentang kebenaran agama yang membawa misi kasih. Mereka menawarkan konsep theologi global, karena menurut tokoh mereka theologi global mempunyai kemampuan lebih dalam menyelesaikan masalah yang telah terjadi berkepanjangan.

Muncul pertanyaan, apakah semacam itu benar?

Bila barat yang diwakili Kristen mempunyai doktrin,'Di luar gereja tiak ada keselamatan.” Juga dipegangi oleh gereja Katholik dan baru awal tahun 1960 Konsili Vatikan II menetapkan doktrin keselamatan umum bagi agama selain Kristen. Ini upaya peletakan landasan teoritis dalam theologi Kristen untuk toleran dalam interaksi dengan umat agama lain.

Pelopor gerakan reformasi pemikiran pluralisme ini Friederich Schleiermacher pada abad 19 [Anis Malik, 2005] Pemikiran pluralisme di barat terus berkembang yang diwakili Arnold Toynbee [1889-1975], Troeltsch, William E.Hoeking memprediksi ke depan makin menguatnya model agama universal.

Menurut WC.Smith, theologi universal dapat dijadikan landasan bersama bagi agama-agama untuk berinteraksi secara damai. Emil Durkhiem berpendapaat bahwa agama muncul sebagai fenomena sosial, oleh sebab itu pada dasarnya semua 
agama sama, sebagai seorang ilmuwan yang mengagungkan akal, itulah pendapat Emil Durkhiem, sama dengan pendapat teman orientalis lainnya.

Demikian ada ilmuwan Muslim yang berpendapat bahwa Al Qur-an sebagai produk budaya Arab, sehingga Al Qur-an tidak lagi sakral, Al Qur-an sah bila diterangkan berdasar akal secara bebas dan tidak sepi dari kritik.

Muhammad Arkoun, Nasher Hamid, Abu Zayd, Muhammad Syahrur tokoh yang mendesakralkan Al Qur-an, artinya Al Qur-an dapat diterangkan secara bebas. Kebebasan mentafsir Al Qur-an hasilnya kesamaan tujuan setiap agama.

Didalam sejarah Islam klasik terdapat pluralis yang umumnya terdiri dari kelompok atau tokoh sufi, mereka berpikir bebas. Ada penulis yang memberi sebutan berpikiran nyleneh, tidak wajar dan keluar dari rel agama karena pendapatnya tidak berlandas hujjah yang benar. Semisal Ibnu Arabi berpendapat bahwa Iblis juga masuk surga dan surganya nomor satu, karena Iblis makhluk yang hanya mau sujud hanya kepada Allah swt. saja, tidak mau sujud kepada Adam as. Oleh karenanya bila sekarang ada tokoh pluralis berbendapat semacam Ibnu Arabi, sebenarnya tokoh tersebut hanya mengulang kembali pendapat Ibnu Arabi.

Nurcholis Madjid seorang ilmuwan Muslim yang mempunyai paham pluralisme sebagaimana pernyataannya sebagai berikut,"....setiap agama sebenarnya merupakan ekspresi keimanan kepada Tuhan yang sama, ibarat roda, pusat roda adalah Tuhan, dan jari-jari itu adalah jalan dari berbagai agama (Budi Handrianto, 2009). Dalam bukunya Budi Handrianto disebut ada sekitar 50 tokoh Muslim yang berpikiran liberal.

\section{Tokoh dan Pendapatnya di Sekitar Pluralisme}

Di depan telah disebut beberapa tokoh dan pendapatnya tentang pluralisme. Sebenarnya dengan pendekatan ilmiah dan obyektif telaah terhadap tokoh tertentu melalui tutur kata, kajian ilmiah yang disajikan atau ditulis dan siapapun bisa membacanya, tidak salah bila orang lain menilainya atau berpendapat atas ideaideanya. Kelemahan seseorang ketika menilai pendapat orang lain akan terjadi bila tolok ukur yang digunakan tidak proporsional, atau ada pada diri penilai kepentingan diri atau ada kecenderungan tidak respek terhadap orangnya.. Contoh dalam hal ini, 
orientalis yang menulis tentang Islam di dalam tulisannya ada semacam melemahkan atau menyalahkan ajaran Islam. HARGibb yang menyebut Islam dengan Mohamadanisme, dia tidak mau menyebut ajaran yang dibawa Kanjeng Nabi Muhammad saw. dengan Islam,, tetapi menyebutnya dengan Mohammadanisme yang artinya keparcayaan kepada Nabi Muhammad saw. atau kepercayaan yang dibawa dan diajarkan oleh Nabi Muhammad saw..

Ada seorang penulis, Kurzman, yang memasukkan dalam karya tulisnya bahwa KH.Ahmad Dahlan dan Syeh Ahmad Syurkati adalah tokoh liberalisme. Alasan apa yang menjadi landasan pendapatnya bahwa dua tokoh Islam tersebut diatas disebut tokoh liberalisme. Justeru L.Stoddart menyebut dua tokoh di atas sebagai modernis dan reformis. Modernis dan reformis sangat berbeda dengan liberalis, karena liberalis ujungnya ke paham pluralisme.

\section{Noercholis Madjid}

Di kalangan perguruan tinggi, Prof.Dr.Noercholis Madjid, yang panggilan akrabnya Cak Nur banyak dikenal sebagai tokoh pluralisme. Lahir di Jombang pada 17 Maret 1939. Semula dia belajar di Pesantren Darul Ulum Rejoso Jombang. Oleh teman-teman santri di pesantren Darul Ulum, Cak Nur kecil mendapat ejekan"anak Masyumi yang kesasar." Yang memang pondok dan lingkungannya berafiliasi ke Nahdliyin, dan adanya pencerahan keagamaaan dalam keluarga mendorong Cak Nur untuk pindah ke Kuliyatul Muallimin al Islamiyah, KMI, Gontor Ponorogo. Di Pondok Gontor Ponorogo inilah pencerahan keagamaan di dapat karena pengasuhannya dalam tataran modern. Dia melanjutkan belajar di IAIN jurusan sastra Arab Syarif Hidayatullah Jakarta. Sarjana Muda, BA, Doktorandus, Drs, dan Doktor filsafat studi Islam di Univesitas of Chicago, Illions, Amerika Serikat 1984. Karya tulis ilmuwan Muslim yang satu ini cukup banyak, sebagai seorang akademisi kegiatan keilmuannya sangat padat di dalam maupun di luar negeri.

Pendiri Yayasan Wakaf Paramadina dan rektor Univesritas Paramadina Mulya Jakarta. Dia meninggal dunia pada hari Senin tanggal 29 Agustus 2005, jam 14.05 WIB. di rumah sakit Pondok Indah Jakarta Selatan. Sakit levernya dibawa berobat ke Cina, dan di sana hatinya dicangkok dengan hati orang Cina, setelah 
pulang ke Jakarta dilanjutkan perawatannya di Singapura, kemudian dibawa pulang dan dirawat di rumah sakit Pondok Indah Jakarta Selatan, disinilah Cak Nur meninggal dunia.

Tahun 1970 dia mengemukakan gagasannya tentang pembaharuan konsep Negara Islam adalah suatu distorsi hubungan proposional antara agama dan negara. Negara adalah salah satu segi kehidupan duniawi yang dimensinya rasional dan kolektif, sedang agama adalah aspek kehidupan yang dimensinya spiritual dan pribadi. Sedangkan Negara yang pantas ditiru sebagai negara teladan adalah Negara Cina Tiongkok.

Makalahnya tentang keharusan pembaharuan pemikiran dan masalah integrasi umat yang anatara lain berisi tentang sekularisasi dan leberalisasi pemikiran Islam. Sekularisasi yang dimaksud bukan penerapan sekularisme dan mengubah kaum Muslimin menjadi sekulair, tetapi untuk menilai yang semestinya duniawi dan melepaskan umat Islam dari kecenderungan untuk menduniawikannya. Sehingga mentalnya siap untuk menguji kembali kebenaan suatu nilai dihadapan kenyataan material, moral maupun historis menjadi sifat Muslim. Dan saat itu yang paling populer pernyataannya,'Islam, yes. Partai Islam, no."

Pidatonya di Universitas-universitas di Eropa, Ramadhan 002,"Islam itu agama hibrida alias cangkokan" Alasannya di dalam Al Qur-an ada lafal qisthas asalnya bahasa Yunani yang artinya adil Juga ada lafal kafura dari bahasa Melayu, artinya kapur barus."

Tahun 1987, dia mengatakan bahwa ," Iblis kelak akan masuk surga yang paling tinggi. Sebab tauhidnya Iblis murni tidak mau sujud kepada Adam as." Saat itu santri-santri Ma'had Al Qalam Pasar Rumput Jakarta mengirim bantahan atas perkataan itu. Tanggapannya Cak Nur,"Santri-santri itu adalah PKI."

Sebenarnya bila saat ini ada orang berpendapat bahwa Iblis nanti akan masuk surga juga,itu yang pasti bukan pendapatnya sendiri, sebab jauh sebelum itu Ibnu Arabi tokoh pluralisme dari kalangan sufi pada zaman Islam klasik juga berpendapat semacam itu. Justeru Cak Nur mengulang pendapatnya Ibnu Arabi, sedang tentang Tuhan dan agama dia berpendapat,"Setiap agama sebenarnya merupakan ekspresi 
keimanan terhadap Tuhan yang sama, ibarat roda, pusat roda itu adalah Tuhan,dan jari-jari itu adalah jalan dari berbagai agama."

Setiap agama merupakan ekspresi keimanan terhadap Tuhan yang sama, ini mengulang pahamnya Jalaluddin Ar Rumi seorang tokoh sufi, bahwa Tuhan-tuhan yang dipercayai dalam setiap agama itu hakekatnya sama Tuhan Yang Maha Aging. Ketokohan pluralisme Jalaluddin Ar Rumi terlihat sampai saat ini, makamnya tidak hanya diziaharahi orang Islam saja, juga banyak orang non Islam menziarahi makamnya untuk memanjatkan doa.

\section{Abdurrahman Wahid}

Siapa yang tidak mengenal KH.Abdurrahan Wahid, dengan panggilan akrabnya Gus Dur, semua warga Negara ini mengenal tokoh yang satu ini, kaena Gus Dur pernah menjadi presiden ke 4 di Negara ini, Republik Indonesia.

Lahir pada tanggal 4 Agustus 1940 di Denanyar, Jombang. Ayahnya bernama K>H.Wahid Hasyim dan ibunya Hj.Shalihah. Diantara sebab nama besarnya sebagai cucu KH.Hasyim Asy'ari pendiri NahdlatulUlama dan dan menjadi presiden ke 4.

Tokoh ini biasa bicara ceplas-ceplos, semisal ingin mengganti ucapan salam, assalamu alaikum warahmatullahi wabarakatuh dengan selamat pagi, siang atau malam.Kata Gus Dur,"Al Qur-an adalah kitab suci porno," adalah pernyataan yang cukup berani.

Ketaqwaan bukan ukuran spesifik dalam Islam. Ketaqwaan yang dimiliki oleh orang non Islam, baik Yahudi, Nasrani maupun yang lain. Ini berdasar firman Allah swt.yang artinya,"Sesungguhnya orang yang paling mulia diantara kamu disisi Allah ialah orang yang paling taqwa,'Q.S.Al Hujurat 13.

Pondok Pesantren Multi Agama Soko Manunggal adalah satu-satunya lembaga pendidikan pesantren multi agama. Dengan misi menjaga kesatuan bangsa dan kerukunan hidup antar umat beragama Forum Keadilan dan Hak Asasi Umat Beragama (Forkhagama) mendirikan pesantrean multi agama di jalan Sendang Guwo Raya, Kelurahan Purwoasri, Mijen, Semarang. 
Menurut Gus Dur pesantren tersebut diharapkan bisa memberikan kebaikan bagi masa depan bangsa yang terpenting menjaga kerukunan antara agama itu tugas semua agama tanpa pandang bulu. Jangan lagi membeda-bedakan agama, ras maupun kerukunan agar negara bisa maju.

Humornya Gus Dur tentang sopir Metro Mini dan juru dakwah.

Di pintu akhirat seorang malaikat menanya sorang sopir Metro Mini," Apa kerjamu selama di dunia ?" Tanya malaikat."Saya sopir Metro Mini, Pak," jawab sopir Metro Mini.Lalu malaikat itu membebri kamar yang mewah untuk sopir Metro Mini tersebut dan peralatannya yang terbuat dari emas.

Lalu datang Gus Dur dengan dituntun ajudannya yang setia."Apa kerja kamu di dunia?, Tanya malaikat kepada Gu Dur. "Saya mantan presiden dan juru dakwah Pak! “ Lalu malaikat memberikan kamar yang kecil dan peralatan dari kayu. Melihat itu Gus Dur protes.

"Pak mengapa kok saya yang mantan presiden sekaligus juru dakwah mendapatkan yang lebih rendah dari seorang sopir Metro Mini? Dengan tenang malaikat itu menjawab,"Begini Pak, pada saat Bapak ceramah, Bapak membuat orang-orang semua mengantuk dan tertidur sehingga melupakan Tuhan. Sedang pada saat sopir Metro Mini mengemudi dengan ngebut, ia membuat orang-orang berdoa."

Dalam perayaan Natal Bersama di Balai Sidang Senayan Jakarta, 27 Desember 1999 M. malam 20 Ramadlan 1420 H, Gus Dur pidato yang antara lain isinya,"...peringatan Natal adalah adalah peringatan kaum Muslinin juga. Kalau kita konsekwen sebagai seorang Muslim merayakan hari kelahiran Nabi Muhammad , juga adalah harus konsekwen merayakan malam Natal. Lebih-lebih pada saat ini, peringatan Natal merupakan sesuatu yang sangat berharga bagi kita, karena yang nerayakan hari Natal berarti kita memperteguh kembali ikatan kita sebagai bangsa Indonesia, kita meneguhkan kembali keyakinan kita bahwa integritas teritorial kita adalah bagian yang mutlak dari kehidupan beragama. 


\section{Ulil Abshar Abdala}

Tokoh muda ini pendiri dan koordinator Jaringan Islam Liberal yang sering disingkat JIL. Lahir 11 Januari 1967 di Pati, Jawa Tengah, ia sebagai intelektual muda NU.

Pendiri JIL ini prinsip leberalnya adalah :Membuka pintu ijtihad pada semua dimensi Islam. Tanpa ijtihad Islam dan ajarannya tidak mampu menjawab berbagai tantangan zaman, semakin maju zaman dalam berbagai bidangnya tantangan yang dihadapi Islam semakin banyak.

Mengutamakan semangat religio-etik, bukan makna literal teks. Penafsiran yang hanya literal akan melemahkan Islam, tidak berkembang kreatif dalam peradaban universal.

Mempercayai kebenaran yang relatif, terbuka dan plural. Penafsiran adalah aktifitas manusia yang kebenarnnya tidak mutlak.Memihak pada yang minoritas dan tertindas dalam arti luas. Struktur sosial politik yang tidak berkeadilan bertentangan dengan semangat Islam yang cenderung menindas yang minoritas.

Kebebasan beragama sebagai yang paling asasi bagi setiap orang, keberagamaan seseorang harus dihargai dan dilindungi. Memisahkan otoritas duniawi dan ukhrawi, otoritas keagamaan dan politik.

Pendapatnya antara lain yang dimuat dalam Majalah Gatra 21 Desember 2002 adalah: "Semua agama sama, semuanya menuju jalan kebenaran. Jadi Islam bukan yang paling benar." Pemahaman serupa juga terdapat di dalam Kristen, selama berabad-abad di dalam Kristen,’Tidak ada jalan keselamatan di luar Gereja. Baru pada tahun 1965, Gereja Katholik di Vatikan merevisi paham ini. Sedangkan Islam yang berusia 1425 tahun dari hijrah Nabi belum memiliki kedewasaan yang sama dengan Katholik."

Pernyataannya yang lain,’Larangan kawin beda agama besifat kontekstual. Pada zaman Nabi, umat Islam sedang bersaing untuk memperbanyak umat. Nah saat ini Islam sudah semilyar lebih kenapa harus takut kawin dengan yang di luar Islam. Islam sendiri sebenarnya sudah mencapai kemajuan kala itu membolehkan laki-laki kawin dengan wanita ahli Kitab.. Ahli Ktab saat ini masih ada. Malah agama-agama 
selain Nasrani dan Yahudipun bisa disebut ahli Kitab. Kawin beda agama hal ini antara perempaun Islam dengan laki-laki non Islam, ssudah tidak relevan lagi.

\section{Islam dan Pluralisme Agama}

Islam agama yang benar, yaitu agama yang kebenarnnya terletak ajaran tauhidnya. Inti keimanan dalam Islam bahwa Allah swt. rabbul alamin, Tuhan yang menciptakan alam semesta. Bukti penciptaan terdapat pada dua ayat Allah swt., yaitu ayat yang difirmankan dalam Al Qur-an dan ayat yang diciptakan dan digelar yang wujudnya alam semesta. Tauhid uluhiyah, ke Maha EsaanNya Allah swt. , Dia satu-satunya Tuhan yang diibadahi, dicintai, ditaati, ditakuti. Selainnya tidak memiliki hak dan sifat ke Tuhanan.

Islam sebagai addin telah diturunkan kepada makhluk ciptaanNya dan hambaNya yang pertama yaitu Adam as., berangsur-angsur diutus sesudahnya Nabi dan Rasul sampai Rasul terakhir Muhammad sw.. Oleh karenanya tidak ada seorang nabi atau Rasul yang ajaran keTuhanannya berbeda, semua sama yaitu Tauhidullah.

Ulama adalah pewaris Nabi, artinya yang melanjutkan perjuangan Nabi yang diutus demikian halnya nabi yang terakhir adalah ulama. Di Indonesia ada Majelis Ulama yang tugasnya antara lain memelihara keIslaman umat Islam memutuskan berdasar Keputusan nomor 7/MUNAS VII/MUI/II/2005, tentang pluralisme,'Pluralisme agama adalah suatu paham yang mengajarkan bahwa semua agama adalah sama dan karenanya kebenaran setiap agama adalah relatif, oleh sebab itu setiap pemeluk agama tidak boleh mengklaim bahwa hanya agamanya saja yang benar sedangkan agama yang lain salah.Pluralisme juga mengajarkan bahwa semua pemeluk agama akan masuk dan hidup berdampingan di surga.

Pluralisme sebagaimana dimaksud semacam tadi adalah paham yang bertentangan dengan ajaran agama Islam. Umat Islam haram mengikuti paham pluralisme. Demikian pokok keputusan Majelis Ulama Indonesia yang tentunya itu mengikat untuk seluruh umat Islam.

Dalam aqidah dan ibadah, umat Islam wajib bersikap eksklusif, dalam arti haram mencampur adukkan aqidah dan ibadah pemeluk agama lain. Sikap pemeluk agama apapun pasti meyakini dan mengakui agama yang dipeluk sebagai agama 
yang benar. Demikian pemeluk agama Islam meyakini Islam sebagai agama yang benar, bahkan satu-satunya agama yang benar. Sebagaimana yang difirmankan Allah swt. yang terjemahnya,"Sesungguhnya agama yang benar di sisi Allah swt haanyalah Islam.”Q.S.Ali Imran 19.

"Barangsiapa mencari agama selain Islam, maka sekali-kali tidaaklah akan diterima(agama itu) daripadanya, dan di akhirat termasuk orang-orang yang rugi.”Q.S.Ali Imran 85.

Diriayatkan dari Abu Hurairah dari rasulullah saw. Bahwa beliau bersabda, "Hujjah di atas secara tekstual dan kontekstual menegaskan kebenaran Islam dn pluralisme agama yang dilahirkan oleh paham leberalisme sebagai paham yang haramkan oleh Islam.”

Setiap agama tentu berbeda dengan agama lain, walau ada kemungkinan pada bagian tertentu ajarannya ada yang sama, ini bias terdapat pada hubungan antar manusia karena manusia makhluk social. Perbedaan yang mendasar paa seiap agama terletak pada kitab sucinya, ajaran ke Tuhannya, ajaran tentangibadahnya atau penyembahnan terhadap yang dituhankan, maklhuk pilihan yang dutus, ajran kehidupan sesudah mati.

KeTauhidan dalam Islam berbeda dengan ke Tuhannan agama selainnya. Menyamakan Allah swt. dengan Tuhan-Tuhan diluar Islam beresiko syirik. Artinya bila seorang Muslim juga percaya kepda Tuhan di luar Islam maka berdosa besar yang tidak mendapat ampunan dari Allah swt. bila sebelum matinya tidak mentaubatinya atau memohon ampun kepada Allah swt. dengantaubatan nashuha.

Al Qur-an berbeda dengan kitab suci agama non Islam, tetapi Al Qur-an sama dengan Taurat, Zabur dan Injil yag asli, memang Allah swt. telah mewahyukan kepada Nabi dan Rasulnya yang harus diimankan oleh umatnya nabi Muhammad saw. Sedamng Taurat, zabur, dan Injil uyang sekarang sering disebut Boble sudah tidakasli lagi.

Forum Kiai Muda Nahdlatul Ulama Jawa Timur menyatakan sikap 8 butir hasil dialognya,salah satunya menegaskan tentang pluralisme agama bertentangan dengan aqidah ahlus Sunnah wal jama'ah.. Dengan paham pluralisme menanamkan ketidakpercayaan kepada ulama salaf dan bahkan mendekontruksi apa yang telah 
diwariskan oleh ulama salaf. Sedaang ulama salaf adalah pewaris Nabi yang harus di-ittiba-i.

Sedang Majelis Ulama Jawa Timur menolak pemberian gelar,’Bapak Pluralisme"'kepada Gus Dur, yang disampaikan Presiden Susilo bambang Ydhoyono ketika memimpin acara pemakaman jenazah Gus Dur di jombang Jawa Timur, Kaamis 31 Desember 2009 "Kami tidak sependapat jika Gus Dur disebut sebagai Bapak Pluralisme seperti diungkapkan Presiden diJombang beberapa waktu yang lalu karena dapat menimbulkan konflik agama. Pluralisme adalah paham pencampuradukkan beberapa ajaran agama sehingga sangat berbahaya terhadap kehidupan beragama di Indonesia."

Ilmuwan Muslim dengan paham pluralismenya sadar atau tidak sadar merusak aqidahnya orang Islam, sebagaimana orang-orang kafir Quraisy yang menginginkan agar Nabi Muhammad saw. juga mengakui Tuhan mereka, tetapi beliau menolaknya.

Allah swt. berfirman, yang artinya,'Dan sesungguhnya mereka hampir memalingkan kamu dari apa yang telah Kami wahyukan kepadamu, agar kamu membuat yang lain secara bohong terhadap Kami. Dan kalau sudah begitu tentulah mereka mengambil kamu menjadi sahabat setia. Dan kalau Kami tidak memperkuat hatimu, niscaya kamu hampir condong sedikit kepada mereka, kalau terjadi demikian, benar-benar Kami akan rasakan kepadamu (siksaan)berlipat ganda di dunia ini dan pula siksaan berlipat ganda sesudah mati, dan kamu tidak akan mendapati seorang penolongpun terhadap Kami."Q.S.Al Isra' 73-75.

\section{Kesimpulan}

Merujuk pada pembahasan di depan, maka dapat disimpulkan bahwa

1. Pluralisme agama adalah gagasan dan paham sebagian kecil dari ilmuwan dari agama-agama besar, semisal Yahudi, Kristen, dan Islam. Dapat dikatakan bahwa tidak semua tokoh agama pada masing-masing agama berpaham pluralisme.

2. Agama yang satu dengan agama yang lainnya itu berbeda, karena pokok atau dasar ajaran agama tidak ada yang sama, apalagi konsep atau ajaran keTuhanan masing-masing agama tidak ada yang sama. 
3. Menyamakan agama-agama karena hakekat Tuhan dalam setiap agama sama walau nama Tuhan berbeda, adalah upaya mendekontruksikan ajaran agama dan sikap ragu terhadap kebenaran agama yang dipeluk.

4. Islam adalah agama yang benar yang sudah diturunkan sejak diutusnya manusia dan Nabi yang pertama yaitu Adam as dan Nabi serta Rasul sesudahnya bersambung bagaikan mata rantai yang tidak terputus yang ajarannya sama dalam menTauhidkan Allah swt.

5. Muslim yang berpaham pluralisme,melekat pada pribadinya sikap mensekutukan Allah swt. dengan yang lain sehingga disebut musyrik dan dosa besar ini tidak akan mendapat ampunan dari Allah swt. bila sampai mati belum ditaubati.

\section{Daftar Pustaka}

Anis Malik Thoha, Tren Pluralisme Agama Tinjauan Kritis, Cet.I, Gema Inani, Press, Agustus 2005.

Budi Handrianto, 50 Tokoh Islam Leberal Indonesia, Cet.VI, Hujjah Press, Jakarta, Juli 2009

Hamka, Tafsir Al Azhar, II, Panjimas, Jakarta

Hartono Ahmad Jaiz, Kiyai Kok Bergelimang Kemusyrikan, Pustaka Nahi Munkar, Jakarta, 2008

.,Ada Pemurtadan di IAIN, Pustaka Al Kautsar,Cet.III, Jakrta, 2006

.,Mengungkap Kebatilan Kiyai Liberal Cs.,Cet.I, Pustaka Al Kautsar, Jakarta Timur, 2010

,Aliran dan Paham Sesat di Indonesia,, Cet.II, Pustaka Al Kautsar, Jakarta Timur, 2010

Muhammad Imarah, Islam dan Pluralitas, Perbedaan dan Kemajemukan dalam Bingkai Persatuan, Terjemah Abdul Hayyie Al Kattamie, Gema Insaan Press, Cet.I, Jakarta 1999

Syakh Muhammad bin Jamil Zainu, Jalaan Golongan Yang Selamat, Terjemah Ainul Haris Umar Arifin Lc, Darul Haq, Cet.XVIII, Jakrta,2012 